Discussion Paper No. 08-122

\title{
Liberalization of the Postal Service Market in Europe: Entry with Universal Service and Partial Coverage
}

Patrick F.E. Beschorner

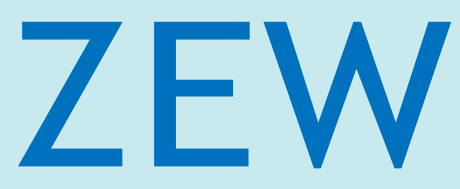

Zentrum für Europäische Wirtschaftsforschung $\mathrm{GmbH}$

Centre for European

Economic Research 
Discussion Paper No. 08-122

\title{
Liberalization of the Postal Service Market in Europe: Entry with Universal Service and Partial Coverage
}

\author{
Patrick F.E. Beschorner
}

Download this ZEW Discussion Paper from our ftp server:

ftp://ftp.zew.de/pub/zew-docs/dp/dp08122.pdf

Die Discussion Papers dienen einer möglichst schnellen Verbreitung von neueren Forschungsarbeiten des ZEW. Die Beiträge liegen in alleiniger Verantwortung der Autoren und stellen nicht notwendigerweise die Meinung des ZEW dar.

Discussion Papers are intended to make results of ZEW research promptly available to other economists in order to encourage discussion and suggestions for revisions. The authors are solely responsible for the contents which do not necessarily represent the opinion of the ZEW. 


\section{Non-technical Summary}

In the advent of postal market liberalization in several European countries this analysis provides an understanding in which dimensions entering firms will compete with the incumbent and how incumbents may act when they anticipate entry. These insights are valuable as a regulatory framework has to be set up in every country in order to ensure Universal Service, as required by European Regulation.

The present model considers entry in a market with vertical differentiation and a geographical dimension where the incumbent firm is required to meet the Universal Service Obligation (USO). That is the obligation to provide a minimum standard, to cover the entire geographic area and to set a uniform, non-discriminatory price. In equilibrium the entrant will offer a higher quality than the incumbent and it will limit its geographical coverage to low-cost areas such as densely populated areas. The limited geographical entry prevents tough price competition, but the incumbent will raise its quality. Thus, the incumbent's customers enjoy higher quality and the entrants' customers receive even higher quality. While consumers benefit the entrant replicates the distribution network. Considering these costs the welfare effect is ambiguous.

The experience from already liberalized markets, e.g. Germany, and the model results imply that one can expect a quality increase by the incumbent and an even higher level of service by the entrants. This effect may be realized prior to the effective liberalization date if the incumbent anticipates entry. Since market entry entails only limited specific investments, anticipated entry or potential competition should force the incumbent to raise its quality. Further, the prospect of higher quality may justify the cost borne by the entrants in replicating the distribution network. 


\section{Zusammenfassung}

Kurz vor der Öffnung des Postmarktes in mehreren Europäischen Ländern zeigt diese Untersuchung, wie eintretende Unternehmen ihre Strategie wählen werden und wie bestehende Postunternehmen reagieren, wenn sie Markteintritt antizipieren. Diese Erkenntnisse sind hilfreich, wenn vor der vollständigen Liberalisierung die nationalen Rahmenbedingungen festgelegt werden müssen, damit die Universaldienstleistung gemäß den Europäischen Vorgaben weiterhin gewährleistet ist.

In der vorliegenden Untersuchung steht der Markteintritt durch ein neues Unternehmen auf einem Markt mit vertikaler Differenzierung im Vordergrund. Dabei kann das neue Unternehmen seine Qualität und die Größe seines Versorgungsgebietes aussuchen. Auf diesem Gebiet muss weiterhin das etablierte den Universaldienst sicher stellen. Die Universaldienstverpflichtung umfasst das Erbringen einer Mindestqualität für das gesamte Versorgungsgebiet $\mathrm{zu}$ einem einheitlichen Preis. Im Modellgleichgewicht bietet das eintretende Unternehmen eine höhere Qualität als das etablierte Unternehmen an und es versorgt nur einen Teil des gesamten Versorgungsgebietes. Das eintretende Unternehmen wird sich auf Gebiete beschränken, die mit geringen Kosten zu versorgen sind, beispielsweise dicht besiedelte Gebiete. Durch diese Beschränkung wird der Anreiz zu starkem Preiswettbewerb durch das etablierte Unternehmen vermindert. Dafür wird dieses eine leichte Qualitätserhöhung vornehmen. Insgesamt erhalten die Konsumenten in jedem Fall eine höhere Qualität. Das eintretende Unternehmen muss Eintrittskosten auf sich nehmen, wenn das Netzwerk des etablierten Unternehmens zumindest teilweise nachbilden muss. Daher ist der gesamte Wohlfahrtseffekt nicht eindeutig.

Die Modellergebnisse und die Erfahrung aus bereits liberalisierten Märkten zeigen, dass man Markteintritt mit höherem Qualitätsniveau als dem Universaldienst erwarten darf. Die Qualitätserhöhung kann auch schon vor der 
Liberalisierung eintreten, wenn der Markteintritt antizipiert wird. Wenn dies schon vor der Liberalisierung eintritt, dann wird dieser Effekt durch potentiellen Wettbewerb angetrieben. Da bei Eintritt eines neuen Unternehmens auch ein Teil des Netzwerkes repliziert wird, stehen den Qualitätsverbesserungen zu Gunsten der Verbraucher höhere Kosten entgegen. 


\title{
Liberalization of the Postal Service Market in Europe: Entry with Universal Service and Partial Coverage
}

\author{
Patrick F.E. Beschorner*
}

first draft: March 2008, this draft: December 8, 2008

\begin{abstract}
In the advent of postal market liberalization in several European countries we expect that the incumbent operators anticipate entry by competitors who are not required to offer universal service, i.e. coverage of the entire country and uniform pricing. The market for postal service exhibits stronger network effects than in telecommunications because of limited interconnection. In the present paper we model entrants which can opt for a partial geographical coverage and who enter with a higher service quality than the incumbent. This allows to predict possible deterrence or accommodating strategies by the incumbent. We show that dependent on the shape of the network costs and the network effects entrants may either offer a low quality in order to mitigate competition or offer a higher quality in order to restrict the entrant's geographical coverage.
\end{abstract}

Keywords: regulation, liberalization, postal services

JEL: L12, L41, L51

* ZEW Centre for European Economic Research, Mannheim, P.O.Box 1034 43, 68034 Mannheim, Germany, tel. +49-(0)621-1235-175, fax. +49-(0)621-1235-170, beschorner@zew.de. Financial Support from the Research Network for Innovation and Competition (RNIC) is gratefully acknowledged. The author is indebted to Helmut Dietl, Gordon Klein, participants of the Fifth IDEI Conference on Regulation, Competition and Universal Service in the Postal Sector, and participants of the Journee de Microéconomie Appliquée 2008 for helpful comments and suggestions. 


\section{Introduction}

In many countries access to postal service is regulated and the universal service obligation (USO) ${ }^{1}$ ensures that any consumer throughout the country has access to a minimum service level. Often the universal service is provided by the incumbent and dominant firm, which is the current or former state monopolist.

USO consists of three key elements: coverage, pricing, and quality. Coverage refers to the geographical dimension. ${ }^{2}$ Usually the USO imposes that the service is to be accessible in the entire country. This regulation may become necessary if the cost of serving a region exceeds the revenue from serving customers in that region. This covers both delivering into this region and picking up mail from this region. Pricing is typically required to be non-discriminatory. This means that an incumbent may not cut prices in a region where entry occurs. A uniform pricing rule ensures that high-cost customers pay the same price as low-cost customers. Consequently, the price of a mail item would not depend on its destination within the region where the USO is binding. The reserved area describes the quality of services that may be offered exclusively by the USO providing firm. This instrument may be used to guarantee sufficient revenue to the USO providing firm.

The complete liberalization of postal markets in Europe is scheduled for 2009. Some countries have already now open markets where any firm is allowed to provide any postal service. The liberalization process may be done gradually such that the reserved area is reduced stepwise. This has already been done so in Germany where by 2008 the exclusive right to deliver letters below 50 grams has been lifted. But already before this date it was possible to obtain a license for these items under certain conditions concerning the minimum quality level of the service. Basically, the minimum service quality

\footnotetext{
${ }^{1}$ See Valletti (2000).

${ }^{2}$ See Valletti et al. (2002), Geradin and Sidak (2005).
} 
that is required by the USO was exclusive to the incumbent firm where competitors were allowed to enter in the market if they offered a significantly higher quality.

Whereas the UK has adopted a liberalization scheme that is not based on minimum weights of the letter mail rather than on volume, France is adopting the stepwise deregulation according to the EC Directive 2002/39/EC. ${ }^{3}$ Additionally, some exemptions from the directive are in force. ${ }^{4}$ The current national regulation in France is codified in the "Loi no 2005_516 du 20/5/2005 relative à la régulation des activités postales".

In the U.S. there is an upcoming discussion on the privatization of the United States Postal Service (USPS) which now is a federal agency. The suggestions range from a restructuring as a Governmental Agency that serves essential needs of the United States up to full privatization where the company would be controlled by shareholders. ${ }^{5}$ It is difficult to predict the development subsequent to a possible liberalization process. ${ }^{6}$ It would depend on the precise scenario and it would be very sensitive to the effective regulations. There may be effects on service quality ${ }^{7}$ and also the amount of annual subsidies for USPS may be questioned to some extent. ${ }^{8}$ A look at the European markets may help to show possible perspectives from a liberalization of the postal market.

Entry on the liberalized market allows new firms to select geographical areas and to design their strategy without legal restrictions concerning the USO. Coverage, pricing and quality are subject to the discretion of the entrants. Since full geographical coverage is not mandated, entrants can leave

\footnotetext{
${ }^{3}$ Official Journal L 176, 5.7.2002, p.21-25.

${ }^{4}$ See van der Horst (2005).

${ }^{5}$ See Geradin and Sidak (2005).

${ }^{6}$ Alston (2007): "Let us also keep in mind that we really don't know how the post office would change, either for the better or the worse, under a truly free-market scenario".

${ }^{7}$ See Alston (2007).

${ }^{8}$ See Sokol (2003), Geddes (2005).
} 
remote and costly areas to the incumbent USO provider. Moreover, they can focus on densely populated areas or on particular customers with large number of mailings. Thus, raisin picking, also known as cream skimming, is a manifest strategy.

In this paper we focus on entry strategies of firms which do not underly the coverage constraint. This means that an entering firm can compete in all three dimensions mentioned above. Thus, raisin picking will be prevalent. We analyze the incentives of an entrant to select a quality level and the geographical extent of its entry. The next section gives a review of the related literature. Section 3 presents the model and in the following sections 4 and 5 we discuss the results and give a conclusion.

\section{Literature}

The motives for imposing a universal service are manifold. A clear cut definition is not available because it would comprise specifics of the particular national market and the underlying technology. A general characterization is proposed by Cremer et al. (2001) who consider the provision to all consumers with a basic service of good quality at affordable prices as the key elements of USO.

To a large extent the literature on USO focuses on financing issues. For example Choné et al. (2000) analyze the funding of USO in a competitive environment. They distinguish cross-subsidies or taxes when potential entrants either face restricted entry or pay-or-play. In the latter mode it is up to the entrant to either serve the entire market or to pay a compensation and to serve a selective geographical area. This has a potential efficiency gain as long as non-discrimination and ubiquity are not imposed.

A lot of attention is devoted to the financing of USO in network industries like telecommunications where the investments are highly specific and they 
entail sunk costs. ${ }^{9}$ This is to a lesser extent the case in postal markets because the distribution network consists of vehicles and labor force which are less specific and much more flexible. Still, the key element of the USO, namely the provision of service to all consumers is critical in this market, too, because cross-subsidizing may become necessary under a uniform pricing rule. Then, selective omission of certain areas would be profitable but not compatible with USO. In postal service markets the cost of operating an extensive network can be estimated from the perspective of an established incumbent firm or from the perspective of an entering firm. The concepts of net avoided costs and entry pricing, which apply respectively, deliver different estimates. Rodriguez and Storer (2000) provide estimates for the UK but they emphasize that an instrument like entry pricing would not contribute to the question of what the effective costs USO actually are.

The literature on quality differentiation has emerged independently from the discussion of USO. However, there is an immediate link to the discussion on the reserved area where the basic service is offered by the USO provider and competitors may offer a higher service quality. Shaked and Sutton (1982, 1983) have established that a natural oligopoly may arise where two firms vertically differentiate in quality and that no further firm is willing to enter the market. In their model the firms are free to set their quality within a certain range and this results in maximal quality differentiation. The driving force is that differentiation is an instrument to relax competition for customers who differ in their valuation for quality.

Hung and Schmitt (1988) analyze sequential entry with vertical differentiation. They demonstrate that the timing of entry determines how the firms choose the quality. The incumbent firm sets the higher quality because this results in a higher profit. If the second firm faces potential entry it will choose its quality level such that it makes zero profit in order to prevent

\footnotetext{
${ }^{9}$ See Panzar (2000), Gasmi et al. (2000), Rosston et al. (2000).
} 
further entry. The incentive to differentiate vertically is reduced if firms face quality dependent costs. They are introduced by Lutz (1997) but the basic results remain unaltered. Entry by a third firm is analyzed by Donnenfeld and Weber (1992). No matter whether the second and third firm enter simultaneously or sequentially, in both cases (one of) the later entrants offers an intermediate quality and earns higher profit than the firm offering the low quality.

As by regulation like in Germany entry in the postal market can occur only on the high quality segment these models cannot explain the incumbent's strategy when it offers the lower quality. Beschorner (2007) focuses vertical differentiation with sequential entry where the entrant offers the higher quality. However, the more general case where the entrant can select which geographical region to serve will be subject matter of the present analysis.

Finally, selective entry can be considered as raisin picking. This is related to the literature on all-pay auctions where the bidders are asymmetric or they have asymmetric information. Baye et al. (1993) consider a case where a politician grants a prize to one out of several asymmetric lobbyists. The lobbyists compete in bribing the politician. This setting has been generalized by Clark and Riis (1998) for multiple prizes. This is equivalent to the present situation where two firms compete for the same customers but one (the incumbent) is restricted by the uniform pricing and the coverage constraint. The implication from the auction theory is that the better informed or more flexible party, which is the entrant, earns the entire profit on that market segment. However, in the context of differentiated products, we will depart from the winner-takes-all payoff as in Valletti et al. (2002). 


\section{Model}

In this section we present a model of vertical product differentiation where we incorporate the specifics of the postal market on which we are focusing. The first peculiarity is that a network has to be set up before a geographical area can be served. Except for the sorting machines this network does not entail highly specific investments but still it has to be set up prior to price competition.

A second peculiarity of the postal market is that there is very little interconnectivity. Typically, the discussion in telecommunications has to take into account for interconnectivity, i.e. the termination fees that the incumbent obtains if she terminates a call in the area where the entrant has no own network. This is a difference with the postal market where the entrants hardly have interconnections with the incumbent. ${ }^{10}$ Therefore, network effects play a much more important role because besides quality and price, a customer appreciates that he can reach a lot of other people. We will consider these effects in our interpretation.

The current market regulation, where full liberalization is not yet established, prescribes that the USO provider has a reserved area which covers the basic service. Entry is only admissible if the entrant asks for a higher price than the USO. Currently, this price threshold is 2.5 times the price of a standard letter in the fastest category. This implies also that an entrant must offer a higher service quality in order to be competitive. Thus, we model entry where the entrant offers superior quality. This is in contrast to the literature on vertical differentiation presented above. Only after full lib-

\footnotetext{
${ }^{10}$ There is unbundling where entrants are sorting and transporting to an incumbent's sorting station. But those entrants who enter as full service providers do not serve certain areas, rather than having their letters transported by the incumbent firm where the latter is the only operator. Moreover, we observe that entrants cooperate in order to have a larger joint area of coverage.
} 
eralization in 2009 competitors of the USO provider can offer inferior quality at a lower price.

Let $u_{i}=m_{i} \cdot \theta$ denote customer $i$ which consumes $m_{i}$ units of a numéraire and one unit of postal service of quality $\theta$. The amount of $m_{i}$ is given by the income $Y_{i}$ minus the price $p$ of the service such that the consumer's utility is

$$
u_{i}=\left(Y_{i}-p\right) \theta
$$

Consumers differ by their initial income $Y_{i}$. They have unit mass which is uniformly distributed on the interval $[a ; b]$. Furthermore, consumers are geographically distributed on the interval $x \in[0 ; 1]$. We assume that the distribution of $Y$ and $x$ are independent. The consumers differ by the cost of serving them.

$$
C(x)=\int_{0}^{x} c(x) d x
$$

where $c(x)$ is the cost of serving consumers at location $x$ with $c^{\prime}(x)>0$. This means that more remote (rural) areas $(x \rightarrow 1)$ are more costly to serve.

The firms offer quality $\theta$ within the interval $\left[\theta_{r}, \bar{\theta}\right]$, where $\theta_{r}$ is the reservation utility that is available to all consumers at price zero. We assume that two firms $j=I, E$, the incumbent and the entrant, choose their product quality and their price $p_{j}$. Imagine that $x \rightarrow 0$ is an urban area and $x \rightarrow 1$ is rural.

The basic quality is the reserved area of the incumbent, thus $\bar{\theta} \geq \theta_{E}>$ $\theta_{I} \geq \theta_{r}$ and $p_{E}>p_{I}$.

\subsection{Unconstrained Equilibrium}

The firms have to decide on their quality and their price. Additionally, the entrant has to choose his entry intensity $x$. The timing of the decisions 
is as follows: First, the incumbent sets her quality $\theta_{I}$. Subsequently, the entrant chooses $x$ and his quality $\theta_{E}$. Finally, both firms simultaneously compete in prices. We will discuss in detail the pricing decision before we can substantiate sensible strategies for the quality and coverage decisions.

In the first step, we determine the demand that the two firms face with respect to their pricing decision. Consumers face the choice between two products $\theta_{I}, \theta_{E}$ and the outside option $\theta_{r}$. Let

$$
\begin{array}{r}
\left(Y_{1}-p_{E}\right) \theta_{E}=\left(Y_{1}-p_{I}\right) \theta_{I} \\
Y_{1}=\frac{p_{E} \theta_{E}-p_{I} \theta_{I}}{\theta_{E}-\theta_{I}}
\end{array}
$$

define the consumer who is indifferent between purchasing high quality with the entrant and low quality with the incumbent. Further,

$$
\begin{array}{r}
\left(Y_{0}-p_{I}\right) \theta_{I}=Y_{0} \theta_{r} \\
Y_{0}=\frac{p_{I} \theta_{I}}{\theta_{I}-\theta_{r}}
\end{array}
$$

defines the consumer who is indifferent between the basic service and the outside option. Let us denote the price equilibrium to be unconstrained, if $Y_{0} \leq a$. This means that $Y_{1}-a$ is the effective demand of the firm which offers the lower quality: The incumbent sets a low price such that the least income consumer is still willing to buy her product instead of the outside quality.

This allows to formulate the demand and the profit functions. Given that all the consumers purchase with either the incumbent or the entrant the demand for the higher quality $\theta_{E}$ is

$$
b-\frac{p_{E} \theta_{E}-p_{I} \theta_{I}}{\theta_{E}-\theta_{I}}
$$

and for the lower quality it is

$$
\frac{p_{E} \theta_{E}-p_{I} \theta_{I}}{\theta_{E}-\theta_{I}}-a
$$


Thus the two firms' profits are

$$
\begin{array}{r}
\pi_{E}=\left(b-\frac{p_{E} \theta_{E}-p_{I} \theta_{I}}{\theta_{E}-\theta_{I}}\right) p_{E} x-C(x) \\
\pi_{I}=\left(\frac{p_{E} \theta_{E}-p_{I} \theta_{I}}{\theta_{E}-\theta_{I}}-a\right) p_{I} x+(1-x)(b-a) p_{I},
\end{array}
$$

respectively. We assume that the incumbent's network costs are sunk. The profit maximizing prices are

$$
\begin{gathered}
p_{E}=\left(\frac{2 b-a}{3}+\frac{1-x}{x} \frac{b-a}{3}\right) \frac{\theta_{E}-\theta_{I}}{\theta_{E}} \\
p_{I}=\left(\frac{b-2 a}{3}+\frac{1-x}{x} \frac{2}{3}(b-a)\right) \frac{\theta_{E}-\theta_{I}}{\theta_{I}}
\end{gathered}
$$

and the profits are

$$
\begin{aligned}
\pi_{E}= & \overbrace{\left(\frac{2 b-a}{3}+\frac{1-x}{x} \frac{b-a}{3}\right)^{2} \frac{\theta_{E}-\theta_{I}}{\theta_{E}}}^{R} x-C(x) \\
& \pi_{I}=\left(\frac{b-2 a}{3}+\frac{1-x}{x} \frac{2}{3}(b-a)\right)^{2} \frac{\theta_{E}-\theta_{I}}{\theta_{I}} x .
\end{aligned}
$$

This is the unconstrained equilibrium in the sense that the low income group will still buy with the incumbent at the price that the incumbent is asking. We have set out that $Y_{0}$ is the indifferent customer between the low quality $\theta_{I}$ and $\theta_{r}$, which is the reservation quality. Thus, we have to assure that the customers with the least income are still willing to purchase $\theta_{I}$ with the incumbent at price $p_{I}$.

Lemma 1 If the income spread is not too wide, the least income group will still purchase with the incumbent.

\section{Proof}

$$
Y_{0}=\frac{p_{I} \theta_{I}}{\theta_{I}-\theta_{r}} \leq a
$$


where

$$
\left(\frac{b-2 a}{3}+\frac{1-x}{x} \frac{2}{3}(b-a)\right) \frac{\theta_{E}-\theta_{I}}{\theta_{I}}
$$

is equivalent to

$$
a \geq b \frac{(2-x)\left(\theta_{E}-\theta_{I}\right)}{2\left(\theta_{E}-\theta_{I}\right)+3 x\left(\theta_{I}-\theta_{r}\right)}
$$

or

$$
\frac{a}{b} \geq \frac{(2-x)\left(\theta_{E}-\theta_{I}\right)}{2\left(\theta_{E}-\theta_{I}\right)+3 x\left(\theta_{I}-\theta_{r}\right)} \equiv R H S
$$

From

$$
\frac{\partial R H S}{\partial x}=-2\left(\theta_{E}-\theta_{I}\right) \frac{2 \theta_{E}+\theta_{I}-3 \theta_{r}}{\left(2\left(\theta_{E}-\theta_{I}\right)+3 x\left(\theta_{I}-\theta_{r}\right)\right)^{2}}<0
$$

we see that

$$
\begin{aligned}
\frac{a}{b} & \geq 1 \text { for } x=0 \\
\frac{a}{b} \geq \frac{\theta_{E}-\theta_{I}}{2\left(\theta_{E}-\theta_{I}\right)+3\left(\theta_{I}-\theta_{r}\right)} & <\frac{1}{2} \quad \text { for } \quad x=1
\end{aligned}
$$

Thus, for

$$
2 a>b
$$

and for some range of $2 a<b$ (but always $b>a$ ) with the unconstraint equilibrium the least rich customers are always served.

The intuition is that if consumers do not differ very much in their preferences, there is no room for exploiting groups with high willingness to pay to the detriment of low-income (low-valuation) customers who would not be served anymore.

This result corresponds to Hung and Schmitt's (1988) Lemma 1 for $x=1$, i.e. when the entrant covers the full market. It holds for $x=1$ and also for 
$x<1$ if $x$ is not too small because otherwise some consumers may refrain from purchasing at all and recur on the reservation service quality $\theta_{r}$.

In order to substantiate the strategies for small $x$, i.e. when the entrant selects only a small geographical area where the network costs are low, we need to know under which conditions the unconstrained equilibrium holds. We will determine the conditions for the incumbent's price to be the lowest while still the entire demand is served, i.e. no consumer recurs on the reservation quality $\theta_{r}$. Thus, we have to find out when $p_{E}>p_{I}$ given that $\theta_{E}>\theta_{I}$

$$
\begin{aligned}
& p_{E}>p_{I} \\
&\left(\frac{2 b-a}{3}+\frac{1-x}{x} \frac{b-a}{3}\right) \frac{\theta_{E}-\theta_{I}}{\theta_{E}}>\left(\frac{b-2 a}{3}+\frac{1-x}{x} \frac{2}{3}(b-a)\right) \frac{\theta_{E}-\theta_{I}}{\theta_{I}} \\
& \Leftrightarrow \quad L H R \equiv \frac{b x+b-a}{-b x+2 b-2 a}>\frac{\theta_{E}}{\theta_{I}} \\
& \Leftrightarrow \quad x \quad>\frac{\left(2 \theta_{E}-\theta_{I}\right)(b-a)}{\left(\theta_{E}-\theta_{I}\right) b} .
\end{aligned}
$$

This condition holds when the firms offer similar qualities or when the consumers do not differ too much in their income and their preference for quality.

When conditions (10) and (11) hold we are now able to show

Proposition 1 Proof: Firms can set their qualities such that the subsequent pricing stage yields full market coverage where all types of consumers $Y_{i} \in$ $[b ; a]$ are served.

(11) must hold. Thus it is sufficient to show that

$$
x=\frac{2(b-a)\left(\theta_{E}-\theta_{I}\right)}{3 a\left(\theta_{I}-\theta_{r}\right)+b\left(\theta_{E}-\theta_{I}\right)}>\frac{1}{2} \frac{b-a}{b}
$$

lies in a sensible range for $x$. Transforming (12) yields

$$
\frac{b}{a} \geq \frac{\theta_{I}-\theta_{r}}{\theta_{E}-\theta_{I}} .
$$


Since $\theta_{E}>\theta_{I} \geq \theta_{r}$ we can always find $\theta_{I}$ small enough to meet this condition.

Conditions (10) and (11) can be written as

$$
\begin{gathered}
\quad x \geq \frac{2(b-a)\left(\theta_{E}-\theta_{I}\right)}{b\left(\theta_{E}-\theta_{I}\right)+3 a\left(\theta_{I}-\theta_{r}\right)} \equiv \Phi_{1} \\
\text { and } \quad x \geq \frac{\left(2 \theta_{E}-\theta_{I}\right)(b-a)}{\left(\theta_{E}-\theta_{I}\right) b} \equiv \Phi_{2}
\end{gathered}
$$

respectively. We can easily see that for $\theta_{I} \rightarrow \theta_{E}$ the first condition becomes binding because $\Phi_{1}$ becomes negative. For $\theta_{I} \rightarrow \theta_{r}$ the second condition becomes binding because $\Phi_{2}$ is becoming larger.

\subsection{Quality and Coverage}

In this section, we analyze the decision in the second stage by the entrant on his coverage and his quality. Further, we substantiate the incumbent's quality decision in the first stage.

Prior to the pricing stage the firms set their qualities: First the incumbent sets $\theta_{I}$ and subsequently the entrant chooses $\theta_{E}$ and $x$. Thus, the entrant takes $\theta_{I}$ as given.

From (8) we immediately see that the entrant chooses the maximum quality $\theta_{E}=\bar{\theta}$. We know from Lutz (1997) that quality dependent costs would limit the incentive to raise quality but this would not alter the qualitative results. Therefore the exogenous upper bound $\bar{\theta}$ is appropriate in the present context. This is equivalent to a quality cost function 0 for $\theta_{E} \geq \bar{\theta}$ and $\infty$ otherwise.

Given $\theta_{I}$, the entrant's choice of quality $\theta_{E}=\bar{\theta}$ determines the revenue $R\left(\theta_{I}, \theta_{E}\right)=R\left(\theta_{I}, \bar{\theta}\right)$ that the entrant realizes at location $x$ according to (8). 
The profit is given by

$$
\pi_{E}\left(\theta_{I}\right)=\int_{0}^{x} R\left(\theta_{I}, \bar{\theta}\right) d x-C(x)
$$

and maximizing the profit with respect to $x$ yields the optimal coverage for the entrant, $\tilde{x}$. This is determined by

$$
R\left(\theta_{I}, \bar{\theta}\right)=c(\tilde{x})
$$

This implies that the entrant can bear the cost of larger coverage if the revenue at each location is higher. On the marginal market the local revenue equals the marginal network costs like in Valletti et al. (2002). Thus,

$$
\tilde{x}\left(\theta_{I}\right)=c^{-1}\left(R\left(\theta_{I}, \bar{\theta}\right)\right)
$$

depends on $\theta_{I}$ with $\partial \tilde{x}\left(\theta_{I}\right) / \partial \theta_{I}<0$.

Now we can turn to the first stage of the game where the incumbent sets the optimal quality $\theta_{I}$.

The incumbent firm has to consider two effects of the quality choice $\theta_{I}$ in the first stage. First, the direct effect follows from (9) where lower quality raises the profit. The reason is that the firms serve more differentiated groups of consumers and this relaxes competition for the pivotal consumers. The second affects indirectly the incumbent's profit through the entrant's coverage decision. A lower quality would raise the entrant's profit through the reduced competition intensity. The higher profit would induce entry at a higher scale, i.e. a higher coverage rate $x$ and this would lower the incumbent's profit.

The two effects work in opposite directions and as long as they do not cancel out one of them will dominate such that the incumbent will either offer the lowest quality $\theta_{I}=\theta_{r}$ or an intermediate quality $\tilde{\theta}$. In the latter case the incumbent does not choose the maximum quality $\bar{\theta}$ that the entrant would choose because of two reasons. First, the incumbent's profit would tend to zero for $\theta_{I} \rightarrow \theta_{E}=\bar{\theta}$. Second, a small value of $x$ relaxes price competition 
such that the conditions (11) and (12) would not hold anymore. But within the admissible range for $x$ defined by these two conditions we can infer that

Proposition 2 A rise in quality by the incumbent is an effective instrument to limit the coverage of the entrant.

Proof: (14) combines the effect of the incumbent's quality on the entrant's revenue with the shape of the coverage cost function $C(x)$. If the latter function is flat, i.e. $c^{\prime}(x)$ is small, then optimal coverage $x$ is highly sensitive with respect to a change in $R\left(\theta_{I}, \bar{\theta}\right)$ and the indirect effect dominates the direct effect.

Denote the entrant's coverage for $\theta_{I}=\theta_{r}$ by $\tilde{x}_{2}$ and her coverage for $\theta_{I}=\tilde{\theta}$ by $\tilde{x}_{1}$.

\subsection{Network Effects}

So far we have not considered network effects. In the postal market this effect is much more prevalent than in other markets, e.g. telecommunications for several reasons. First, we hardly observe interconnection. While a phone call departing from a small network will be terminated through the incumbent's network, in postal services this is not common. In order to realize network effects several entrants which are active on distinct geographical markets can cooperate in order to offer a larger service area to their customers. Secondly, consumers dislike to contact several operators and to verify whether an addressee can be reached via a particular operator. A large coverage makes it less probable for a consumer that he has to use several postal service operators. Finally, their may be switching costs which a consumer is more willing to incur, if the entering firm offers a large coverage.

We introduce network effects in a very stylized manner in (13)

$$
\pi_{E}\left(\theta_{I}\right)=\int_{0}^{x} R^{n}\left(\theta_{I}, \bar{\theta}, x\right) d x-C(x)
$$


with $\partial R^{n} / \partial x>0, \partial^{2} R^{n} / \partial x^{2}<0$. The network effect results in an concavely increasing marginal revenue.

Since the marginal consumers have a higher willingness to pay the entrant can realize a higher revenue at each location $x$. Therefore $R^{n}>R$ for all $x>0$. Thus, the entrant can bear higher marginal network cost $c(x)$, given the qualities $\theta_{I}, \theta_{E}$. Consequently, both accommodating and deterring entry by the incumbent results in higher coverage levels $\tilde{x}_{1}^{n}>\tilde{x}_{1}$ and $\tilde{x}_{2}^{n}>\tilde{x}_{2}$. These properties imply that

Proposition 3 Network effects strengthen the incumbent's incentive to constrain the entrant's coverage.

Proof: Network effects make entry at a larger scale more attractive to the entrant. To see this, replace $R$ by $R^{n}$ in (13). Further, from the concavity property of $R^{n}(\cdot, \cdot, x)$ we know that $\partial R^{n} / \partial x^{\prime}>\partial R^{n} / \partial x^{\prime \prime}$ for $x^{\prime}<x^{\prime \prime}$. Thus, the entrant's choice of $x$ becomes more sensitive with respect to $\theta_{I}$, making it for the incumbent less costly to constrict the entrant's coverage.

\section{Discussion}

Comparison with full coverage. Under full coverage the entrant and the incumbent serve the same geographical area. While the incumbent has incurred the sunk investment the entrant still needs to do so. This is the situation discussed in Hung and Schmitt (1988) where the entrant offers the lower quality and earns zero profit in order to prevent further entry. The situation where the entrant offers higher quality because this is required by the regulation is analyzed in Beschorner (2007). A rise in quality by the incumbent aims at deterring entry or softening quality and price competition subsequent to the anticipated market entry. 
Constrained equilibrium. We have analyzed market entry with large coverage. The active firms will engage in price competition. Valletti et al. (2002) show that there are two countervailing effects when the entrant enters with smaller coverage: Small entry softens price competition because the incumbent would lose too much revenue on her remaining monopoly region. On the other hand, not competing for the contested area where the entrant is active results in revenue losses, too, which corresponds to the fat cat-property in Fudenberg and Tirole (1984). Given these two effects the latter becomes negligible if the incumbent's coverage is much larger than the entrant's. This may be the case if the entrant is active only in one metropolitan area. Typically, early entrants were newspaper publishers with daily delivery service within a city. This network was built-up in order to deliver mail, too. Therefore, if entry with little coverage occurs, the strategic interaction can be neglected and the entrant faces a large competitor who does not react upon entry. Prior to the liberalization the entrant would offer higher quality if profitable. Eventually, entry may occur at any quality level.

Multiple Qualities Throughout the present analysis we have assumed that the incumbent offers one product with a well-defined quality. In several countries letter mail is offered in two quality categories. In France La Poste offers for international mail two categories: courrier international prioritaire and courrier international économique. Also in the U.S. the United States Postal service offers Priority Mail and First-Class Mail.

Offering multiple qualities is an instrument in order to cover the entire quality range. Thus making is more difficult for entrants to find a niche where they can differentiate. Actually, it is not a peculiarity of these two postal service operators to offer a whole menue of products. However, this gives to the operators the opportunity to offer a product below the standard mail quality, thus covering the needs of distinct types of consumers: price sensitive and quality sensitive. 


\section{Limitations}

There is an intermediate range of coverage by the entrant where the incumbent would like to set a price such that some customers prefer to recur on the reservation quality. In this case the incumbent must take into account that upon liberalization there is room for entrants on the lower quality scale. This is to a lesser extent relevant if the incumbent offers different quality levels. But the analytical framework does not cover this behavior.

Multiple entry is not directly addressed in the present framework. In Hung and Schmitt (1988) the entrant seeks to prevent entry and therefore, being in the position of reacting upon the entrants' commitment on quality. This extension of the model would offer the opportunity to link it to other network industries like broadband telecommunications where it is up to the provider to offer a hole range of bandwidth up to technical limits. Here, competition would arise on the price and on the product range level.

In telecommunications, interconnection is a typical prerequisite for an entrant to operate successfully. Customers face only price competition and there is no need to verify the coverage of an operator with respect to other parties that will receive the customer's phone call. Therefore network effects are much more important on a network with no interconnection. This difference makes it difficult to immediately transpose results from the telecommunications literature on postal services. 


\section{Conclusion}

We have analyzed market entry with vertical differentiation where the entrant can choose his degree of market coverage, thus, leaving a monopoly area to the incumbent. This softens the price competition under the uniform pricing constraint. When anticipating entry the incumbent faces two incentives: raising the quality reduces the entrant's profit and, consequently, the degree of coverage. Reducing the quality, while complying with the USO requirements differentiates from the entrant such that it reduces the competition by serving different types of consumers.

The analysis of USO under free entry and absent from a coverage constraint for the entrant has shown that still all customers may be served. Prices and qualities can be set such that no consumer refrains from demanding the service. Further, the incumbent can raise the quality level in order to reduce the entrant's coverage. Considering the entry costs, the welfare effect is ambiguous because the incumbent's customers receive higher quality while the entrant has fewer customers with the even higher quality. Finally, the presence of network effects reinforces the incentive to compete in qualities rather than in prices. Network effects will also increase the incumbent's incentive to limit the entrant's coverage.

In the advent of complete liberalization of the European postal service market, entry is possible with superior quality than the USO requirement. Since market entry entails only limited specific investments, anticipated entry or potential competition should force the incumbent to raise its quality. Further, the prospect of higher quality may justify the cost borne by the entrants in replicating the distribution network. Subsequent to the final liberalization in 2009 entrants can operate on the full quality range. This will open competition in more dimensions than in the present analysis and, thus, may alter the results. 


\section{References}

Alston, Wilton D. (2007), What Would Happen If the Post Office Had Competition?, in: http://www.lewrockwell.com/alston/alston21.html

Baye, Michael R., Dan Kovenock, Casper G. de Vries (1993), Rigging the Lobbying Process: an application of the All-Pay Auction, in: American Economic Review 83,1, 289-294.

Beschorner, Patrick (2007), Entry Deterrence in Postal Service Markets, ZEW Discussion Paper 07-83.

Choné, Philippe, Laurent Flochel, Anne Perrot (2000), Universal service obligations and competition, in: Information Economics and Policy 12, 249-259.

Choné, Philippe, Laurant Flochel, Anne Perrot (2002), Allocating and funding universal service obligations in a competitive market, in: International Journal of Industrial Organization 1, 1247-1276.

Clark, Derek J., Christian Riis (1998), Competition over More than One Prize, in: American Economic Review 88, 1, 276-289.

Cremer, H., F. Gasmi, A. Grimaud, J.J. Laffont (2001), Universal service: an economic perspective, in: Annals of Public and Cooperative Economics $\mathbf{7 2}, 1,5-43$.

Donnenfeld, Shabtai, Shlomo Weber (1992), Vertical Product Differentiation with Entry, in: International Journal of Industrial Organization 10, 449-472.

Fudenberg, Drew, Jean Tirole (1984) The Fat-Cat Effect, The Puppy-Dog Ploy, and The Lean and Hungry Look, in: American Economic Review 74, Papers and Proceedings, 361-366. 
Geddes, R. Richard (2005), Reform of the U.S. Postal Service, in: Journal of Economic Perspectives 19, 3, 217-232.

Geradin, Damien, J. Gregory Sidak (2005), The Future of the Postal Monopoly: American and European Perspectives After the Presidential Commission and Flamingo Industries, in: World Competition: Law and Economics Review 28, 2,163-198

Horst, Mark van der (2005), Postal Liberalization in the EU - A Small Step in Weights, a Giant Leap for the Market, in: Michael A. Crew, Paul R. Kleindorfer (eds.), Regulatory and Economic Challenges in the postal and delivery sector, Kluwer, New York, 317-332.

Hung, N.M., Nicolas Schmitt (1988), Quality Competition and Threat of Entry in Duopoly, in: Economics Letters 27, 287-292.

Lutz, Stefan (1997), Vertical Product Differentiation and Entry Deterrence, in: Journal of Economics 65, 1, 79-102.

Panzar, John C. (2000), A methodology for measuring the costs of universal service obligations, in: Information Economics and Policy 12, 211-220.

Rodriguez, Frank, David Storer (2000), Alternative approaches to estimating the cost of the USO in posts, in: Information Economics and Policy 12, 285-299.

Rosston, Gregory L., Bradley S. Wimmer (2000), The 'state' of universal service, in: Information Economics and Policy 12, 261-283.

Shaked, Avner, John Sutton (1982), Relaxing Price Competition Through Product Differentiation, in: Review of Economic Studies 49, 3-13.

Shaked, Avner, John Sutton (1983), Natural Oligopolies, in: Econometrica $\mathbf{5 1}, 5,1469-1483$. 
Sokol, D. Daniel (2003), Express Delivery and the Postal Sector in the Context of Public Sector Anti-Competitive Practices, in: Northwestern Journal of International Law \& Business 23, 353-381.

Valletti, Tommaso M. (2000), Introduction: Symposium on universal service obligation and competition, in: Information Economics and Policy 12, 205-210.

Valletti, Tommaso M., Steffen Hoernig, Pedro P. Barros (2002), Universal Service and Entry: The Role of Uniform Pricing and Coverage Constraints, in: Journal of Regulatory Economics 21, 2, 169-190. 